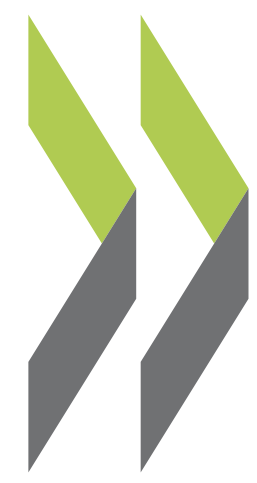

PEB Exchange, Programme on Educational Building 2002/03

\title{
Hungary's Educational Community Centres
}

\section{Lajos Jeney}

https://dx.doi.org/10.1787/753187254125 


\section{HUNGARY'S EDUCATIONAL COMMUNITY CENTRES}

This article describes some current challenges for those making decisions related to educational facilities in Hungary, explains who should be involved in the design process and presents the make-up of the functional units of educational community centres.

\section{Decision-making}

Since 1990, local authorities have been responsible for Hungary's public education institutions, including the design of facilities. An appropriate decision-making process, one that balances the independence of local authorities with professional guidance and backing from the central government, has yet to be developed, as evidenced by the poor quality of educational facilities built since the change of political regimes. For the majority of local authorities, lacking information and professional knowhow, independence equates to having been abandoned.

Nation-wide regulations issued by the central government establish the appropriate building codes and the basic requirements of regional development and town planning, but a well-functioning public building cannot be designed or built on this basis alone. Several controlling authorities have recognised this fact and have taken the necessary steps to develop technical and economic regulations for the institutions under their control. If decisions are made in accordance with real local and social demands, on the basis of modern professional concepts and regulations, then the quality of educational, community and cultural facilities will certainly improve.

\section{Design process}

Hungary's educational community centres are modern public institutions designed to accommodate teaching, educational, cultural and leisure activities for both youth and adults efficiently and economically.

Preparing a design brief for an educational community centre requires co-operation between educational, social and civic representatives, the future users of the facility and the architect. Design briefs established in this way reflect real local demands, and basic requirements of quality control will prevail in planning and design. A good design brief can produce useful buildings with architectural and social value; a bad design brief, on the other hand, can have permanently damaging effects.

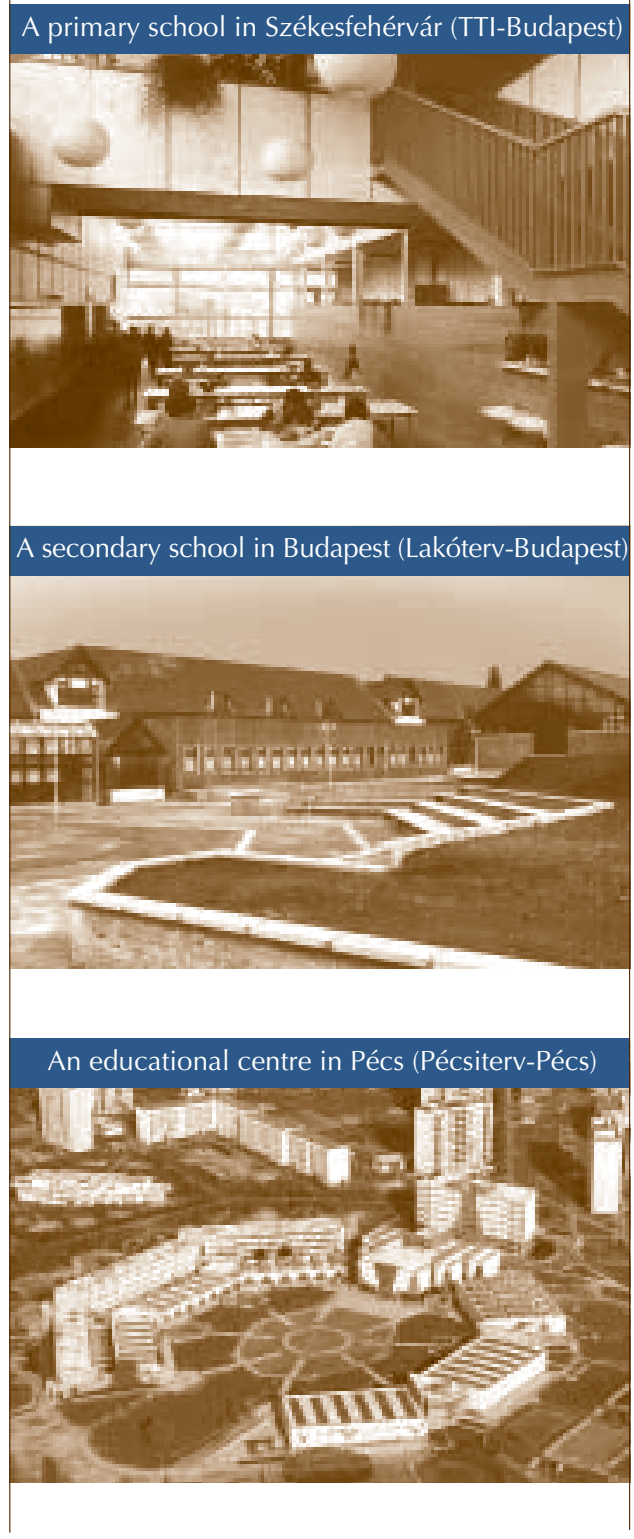

During the subsequent drafting stage, the architect should continue to work with the team of professionals who participated in preparing the design brief. From the point of view of quality, high priority should go to the users. Since the users are rarely able to clearly express their demands in professional architectural terms, it is the architect's task to formulate the demands through dialogue with the users; this process is often difficult. The users discuss their requirements in terms of methodology, educational theory and philosophy, and the architect should reflect these aspects in his or her drawings.

Which users should participate in this dialogue? Theoretically the answer is straightforward: students, teachers, parents, competent officials of authorities and leaders of the local community. In reality, participation of all these partners in the dialogue can hardly ever be organised. In any event, the architect must remain open to all the educational, cultural and community requirements. 


\section{Functional units}

The educational community centre is a modern facility that is especially sensitive to the interrelationship between teaching tools and space. An analysis of the interaction between these two raises the question of flexibility and offers several alternatives:

1. rigidly bound space with multi-use equipment, in which case the same space can serve various functions;

2. varying spatial frames with multi-use equipment, which allows the space to serve more uses than in the preceding case;

3. mobile storage cabinets for teaching tools. In this case, special attention should be given to the design of the circulation area between rooms (e.g. appropriate floor finish) and to the practical design of doors (e.g. doors without thresholds).

The flexible use of space is not merely a technical problem but is also a question of usage. For example when rooms separated by movable partitions will serve for classes, the limited control over sound should be taken into account.

Harmony between furniture, equipment, fittings and architectural design determines the quality of each functional unit and influences its functional value.

Classrooms should be equipped for the use of audio and visual materials controlled from a central studio and have their own compartments to store audio-visual and demonstration materials. The layout of specialist classrooms is largely determined by the location of "fixed points" for water, gas, power, etc. Teaching materials for all subjects of instruction are stored in a single, centrally located room, where specialist teachers have individual workstations for their preparation and research work.

The library not only stores books but also provides a database, scanners, microfilm reader, audio-visual aids and other tools. The size and layout of the library's information centre, reading room and other workplaces, as well as acoustics and lighting are important for good usage of the equipment. The design of the floor, walls and ceiling is mainly defined by acoustical requirements.

A general-purpose workshop should be suitable for working with various materials (wood, metal, synthetic material, paper, etc.) and furnished with up-to-date multipurpose equipment for use by both youth and adults. Separate small booths should be provided where dangerous work such as welding or cutting can be done only under permanent supervision. The construction and finish of the floor, walls and ceiling should be impact and wear resistant and easy to clean. The evaluation of workshops from the viewpoint of acoustics and environmental protection has been neglected in Hungary, therefore much work remains to be done in this field.

Beyond a certain size, the studio centre should be a selfcontained unit in the complex. Producing audio-visual programmes raises serious problems of acoustics and artificial lighting. The design of the floors, walls and ceiling lining must correspond to specific requirements.

In designing the sports area, furnishings and equipment are governed by strict technical regulations. The floor, as the main sports resource, should be designed with special care.

A competition-size gymnasium (for uses from badminton to handball) should have two curtains, extending from sidewall to sidewall and from floor to ceiling, to divide the space into three smaller gymnasiums for school classes.

The multipurpose hall requires careful analysis to determine equipment and usage options. The two most extreme functions should be identified, and the space should be equipped for the functions falling between them. In the functional analysis the starting point should always be the function requiring the most robust constructions. For example when the extremes extend from sports to cultural activities such as theatre, then designing and outfitting should begin with the sports requirements.

The main advantage of a multipurpose facility lies in the fact that with minimal extra expenses for outfitting a single space can appropriately meet many users' demands. As multifunctionality requires much equipment, the importance of mobile storage containers increases. In furnishing, special attention should be given to stackable platform units and seats that are easy to assemble and move.

The site information system occupies an undeservedly neglected place among the resources of educational institutions in Hungary. Information boards should be placed at each entrance. They should give an overview of the whole facility in an easily understandable form and indicate the location of the observer in relation to the whole institution. The system is based on a code of colours, numerals and letters.

Open-air facilities offer space and equipment for different activities - teaching, education, play, rest, leisure and sports for both youth and adults - without requiring extensive resources.

Article by:

Lajos Jeney

Architect

Budapest, Hungary 